\title{
Strontium (II)-Selective Potentiometric Sensor Based on Ester Derivative of 4-tert-butylcalix(8)arene in PVC Matrix
}

\author{
Ajay K. Jain ${ }^{1 *}$, Vinod K. Gupta ${ }^{1}$ and Jitendra R. Raisoni ${ }^{1}$ \\ ${ }^{1}$ Department of Chemistry, Indian Institute of Technology Roorkee, Roorkee-247667, India \\ * Author to whom correspondence should be addressed. Email: akjaincy@iitr.ernet.in, \\ Tel: +91-1332-285809, Fax: +91-1332-273560
}

Received: 1 March 2004 / Accepted: 22 August 2004 / Published: 30 August 2004

\begin{abstract}
Membranes of 4-tert-butylcalix(8)arene-octaacetic acid octaethyl ester (I) as an electroactive material, sodium tetraphenyl borate (NaTPB) as an anion excluder, and tri-n-butyl phosphate (TBP) as a solvent mediator in poly(vinyl chloride) (PVC) matrix have been tried for a strontium-selective sensor. The best performance was exhibited by the membrane having a composition 5:100:150:2 (I: PVC: TBP: NaTPB (w/w)). This sensor exhibits a good potentiometric response to $\mathrm{Sr}^{2+}$ over a wide concentration range $\left(3.2 \times 10^{-5}-1.0 \times 10^{-1} \mathrm{M}\right)$ with a Nernstian slope $(30 \mathrm{mV} /$ decade). The response time of the sensor is $10 \mathrm{~s}$ and it has been used for a period of four months without any drift in potentials. The selectivity coefficient values are in the order of 0.01 for mono-, bi-, and trivalent cations which indicate a good selectivity for $\mathrm{Sr}^{2+}$ over a large number of cations. The useful $\mathrm{pH}$ range for the sensor was found to be 3-10 and it works well in mixtures with non-aqueous content up to $25 \%(\mathrm{v} / \mathrm{v})$. The sensor has been used as an indicator electrode in the potentiometric titration of $\mathrm{Sr}^{2+}$ against EDTA.
\end{abstract}

Keywords: Potentiometric sensor, $\mathrm{Sr}$ (II), ester derivative, calixarenes. 


\section{Introduction}

Strontium is an important alkaline earth metal which finds application in production of glasses for colour television sets and ferrite magnets [1], in refining of zinc and added to tin and lead alloys for increasing hardness and durability [2]. The determination of strontium thus, assumes importance and various instrumental methods for its detection used are atomic absorption spectrometry [3], flame photometry [4], ICP-AES [5], etc. Though these methods do provide an accurate determination, they are not very appropriate for large scale monitoring in view of high cost and requirement of sample pretreatment. In such situations, a potentiometric determination by ion-selective electrodes (ISEs) is desirable. It provides an easy, convenient and low cost procedure of analysis in short time. The analysis by ISEs can be nondestructive, requires low sample volumes and generally no sample pretreatment, and is also applicable to turbid and coloured samples. Thus, the analysis by ISEs is a preferred procedure for those ions for which good ISEs are available.

Researchers in this field had been attempting to prepare ISEs for various ions during the last three decades. However, it has not been possible to have highly selective electrodes available for $\mathrm{Sr}^{2+}$ determination. Several electrodes based on the use of neutral carriers [6-9] and inorganic ion exchangers [10-13] as electroactive phase of the membrane are reported. However, these electrodes have not been found very successful as they exhibit a significant interference to other alkaline earth metals, high response time and function over a limited $\mathrm{pH}$ range. Therefore, it is desirable to further explore different materials for the preparation of membranes which may function as selective sensor for $\mathrm{Sr}^{2+}$. An essential requirement of a material to be employed as an electroactive phase of the membrane is its high specificity for a particular ion. Efforts are, therefore, being made in recent times to use newer materials such as calixarenes, cryptands, porphins, etc. Calixarenes have emerged as selective materials for alkali and alkaline earth metals [14] and therefore, can be fruitfully applied for developing ISEs for these metals. Recently, we have used 4-tert-butylcalix(8)arene for preparing PVC-based membranes to be employed as $\mathrm{Sr}^{2+}$ sensor [15]. The performance of the sensor is comparable with the existing sensors and has not shown a significant improvement in selectivity. Therefore, we have extended our earlier work on the membranes of 4-tert-butylcalix(8)arene by employing its derivative, 4-tert-butylcalix(8)arene-octaacetic acid octaethyl ester, expecting it to show a more specific response behavior towards strontium. It is documented that ester derivatives of calixarenes [16-19] tend to show a better selectivity than the parent calixarene due to the change in cavity size, conformation and increased number of binding sites. The results on the membranes of the derivative of 4-tert-butylcalix(8)arene are presented in this communication and show an improvement in selectivity, $\mathrm{pH}$ range and response time.

\section{Experimental}

\section{Reagents}

4-tert-butylcalix(8)arene-octaacetic acid octaethyl ester (I) was obtained from Acros Organics, USA; high-molecular weight poly(vinyl chloride) (PVC) and tris-(2-ethylhexyl) phosphate (TEP), Aldrich, 
USA; dioctylphthalate (DOP), GSC, India; dibutyl(butyl)phosphonate (DBBP), Mobile, USA; 1chloronapthalene (CN) and tri-n-butyl phosphate (TBP), E. Merck, Germany; sodium tetraphenyl borate (NaTPB),BDH, England were used. Analytical reagent-grade tetrahydrofuran (THF), nitric acid and sodium hydroxide were obtained from Ranbaxy, India. Solutions of different concentration were prepared by diluting the stock solution of $0.1 \mathrm{M}$ concentration.

\section{Preparation of membrane}

$\mathrm{Sr}^{2+}$-selective membranes were prepared by dissolving a mixture of I, anion excluder (NaTPB), plasticizer and PVC in THF. The solution was poured into circular acrylic rings placed on a glass plate and the solvent was then, allowed to evaporate at room temperature. The resulting membrane of $0.5 \mathrm{~mm}$ thickness was obtained. It was then, cut to size and attached to a 'Pyrex' tube with the help of araldite (Ciba Geigy, India) and equilibrated in $0.5 \mathrm{M} \mathrm{Sr}^{2+}$ solution for 2-3 days. A number of such membranes were prepared and those which generate stable potentials and exhibited satisfactory response with regard to working concentration range and slope were selected for further studies. The composition of these membranes is given in Table 1.

\section{Potential Measurements}

The potential measurements were carried out at $25 \pm 0.1{ }^{0} \mathrm{C}$ with a digital potentiometer (Model 5652 A, ECIL, India) and Century Microvoltmeter (Model CVM 301, India) by setting up the following cell assembly, where saturated calomel electrodes (SCE) were used as reference electrodes:

\begin{tabular}{|c|c|c|c|c|}
\hline Internal & Internal & & & External \\
Reference & solution & Membrane & Test solution & Reference \\
Electrode & $0.1 \mathrm{M} \mathrm{Sr}^{2+}$ & & Electrode \\
$(\mathrm{SCE})$ & & & & (SCE) \\
\hline
\end{tabular}

\section{Results and Discussion}

\section{Performance characteristics of sensor}

The potentials of the cells set-up with the sensors having membranes with and without plasticizers were measured in the concentration range of $1.0 \times 10^{-6}-1.0 \times 10^{-1} \mathrm{M}$ of $\mathrm{Sr}^{2+}$ solution and plotted in Figure 1 . The working concentration range and slope for different sensors have been determined from these plots and summarized in Table 1. The sensor No. 1 having a membrane without plasticizer exhibited a narrow working concentration range of $3.2 \times 10^{-4}-1.0 \times 10^{-1} \mathrm{M}$ with a slope $31 \mathrm{mV} /$ decade of concentration. The response time, time taken by the sensor to generate a stable potential, of this sensor was found to be $60 \mathrm{~s}$. Thus, this sensor exhibited a short working concentration range with a slow response and a slope 
slightly higher than Nernstian $(29.5 \mathrm{mV} /$ decade $)$. In order to improve the performance of the membrane, different plasticizers viz. DOP, TEP, 1-CN, TBP and DBBP, were added to the membrane and the results obtained are also given in Table 1. It is seen that all plasticizers tend to improve the working concentration range, lower the response time and decrease the slope except DBBP, which increases it.

Table 1. Composition of PVC membranes of 4-tert-butylcalix(8)arene-octaacetic acidoctaethyl ester and performance characteristics of $\mathrm{Sr}^{2+}$-selective electrode.

\begin{tabular}{|c|c|c|c|c|c|c|c|c|c|c|c|}
\hline \multirow{2}{*}{$\begin{array}{l}\text { Sensor } \\
\text { No. }\end{array}$} & \multicolumn{8}{|c|}{ Composition of the membrane $(\mathrm{w} / \mathrm{w})$} & \multirow{2}{*}{$\begin{array}{l}\text { Working } \\
\text { concentration } \\
\text { range }(\mathrm{M})\end{array}$} & \multirow{2}{*}{$\begin{array}{c}\text { Slope } \\
\text { (mV/dec.) }\end{array}$} & \multirow{2}{*}{$\begin{array}{l}\text { Response } \\
\text { time (s) }\end{array}$} \\
\hline & (I) & PVC & DOP & TEP & DBBP & $\mathrm{CN}$ & TBP & NaTPB & & & \\
\hline 1 & 5 & 100 & & & & & & 2 & $3.2 \times 10^{-4}-1.0 \times 10^{-1}$ & 31.0 & 60 \\
\hline 2 & 5 & 100 & 150 & & & & & 2 & $1.6 \times 10^{-4}-1.0 \times 10^{-1}$ & 27.0 & 45 \\
\hline 3 & 5 & 100 & & 150 & & & & 2 & $1.2 \times 10^{-4}-1.0 \times 10^{-1}$ & 21.0 & 40 \\
\hline 4 & 5 & 100 & & & 150 & & & 2 & $6.3 \times 10^{-5}-1.0 \times 10^{-1}$ & 35.1 & 40 \\
\hline 5 & 5 & 100 & & & & 150 & & 2 & $5.0 \times 10^{-5}-1.0 \times 10^{-1}$ & 24.0 & 30 \\
\hline 6 & 5 & 100 & & & & & 150 & 2 & $3.2 \times 10^{-5}-1.0 \times 10^{-1}$ & 30.0 & 10 \\
\hline
\end{tabular}

A comparison of the performance characteristics of all the sensors clearly revealed that the sensor No. 6 having a membrane with TBP plasticizer is the best as it exhibits the widest concentration range of $3.2 \times$ $10^{-5}-1.0 \times 10^{-1} \mathrm{M}$, an almost Nernstian slope $(30 \mathrm{mV} /$ decade $)$ and a minimum response time of $10 \pm 1 \mathrm{~s}$. Thus, all further studies were carried out with cells employing sensor No. 6. Further, a repeated monitoring of potentials (20 measurements) on any day of investigation at the same portion of the sample $\left(1.0 \times 10^{-3} \mathrm{M}\right)$ gave a standard deviation of $0.2 \mathrm{mV}$. The sensor was fairly stable and was used over a period of four months without showing any drift in potential. However, when not in use, the electrodes were stored in $0.1 \mathrm{M} \mathrm{Sr}^{2+}$ solution.

\section{Effect of $p H$ and non-aqueous medium}

In order to study the effect of $\mathrm{pH}$ on the performance of the sensor, the potentials were determined at two concentrations $\left(1.0 \times 10^{-3}\right.$ and $\left.1.0 \times 10^{-2} \mathrm{M}\right)$ of $\mathrm{Sr}^{2+}$ ions as a function of $\mathrm{pH}$. The $\mathrm{pH}$ of the solution was varied by the addition of $\mathrm{NaOH}$ and $\mathrm{HNO}_{3}$. The results obtained (Figure 2) indicate that the potential remains constant over $\mathrm{pH} 3$ to $\mathrm{pH} 10$. Thus, a useful $\mathrm{pH}$ range for this sensor is 3 to 10 . Below $\mathrm{pH} 3$, the change in the potential is due to cofluxing of hydrogen ions and above $\mathrm{pH} 10$, the decrease in potential appears due to the formation of $\mathrm{SrOH}^{+}$ions [20]. 


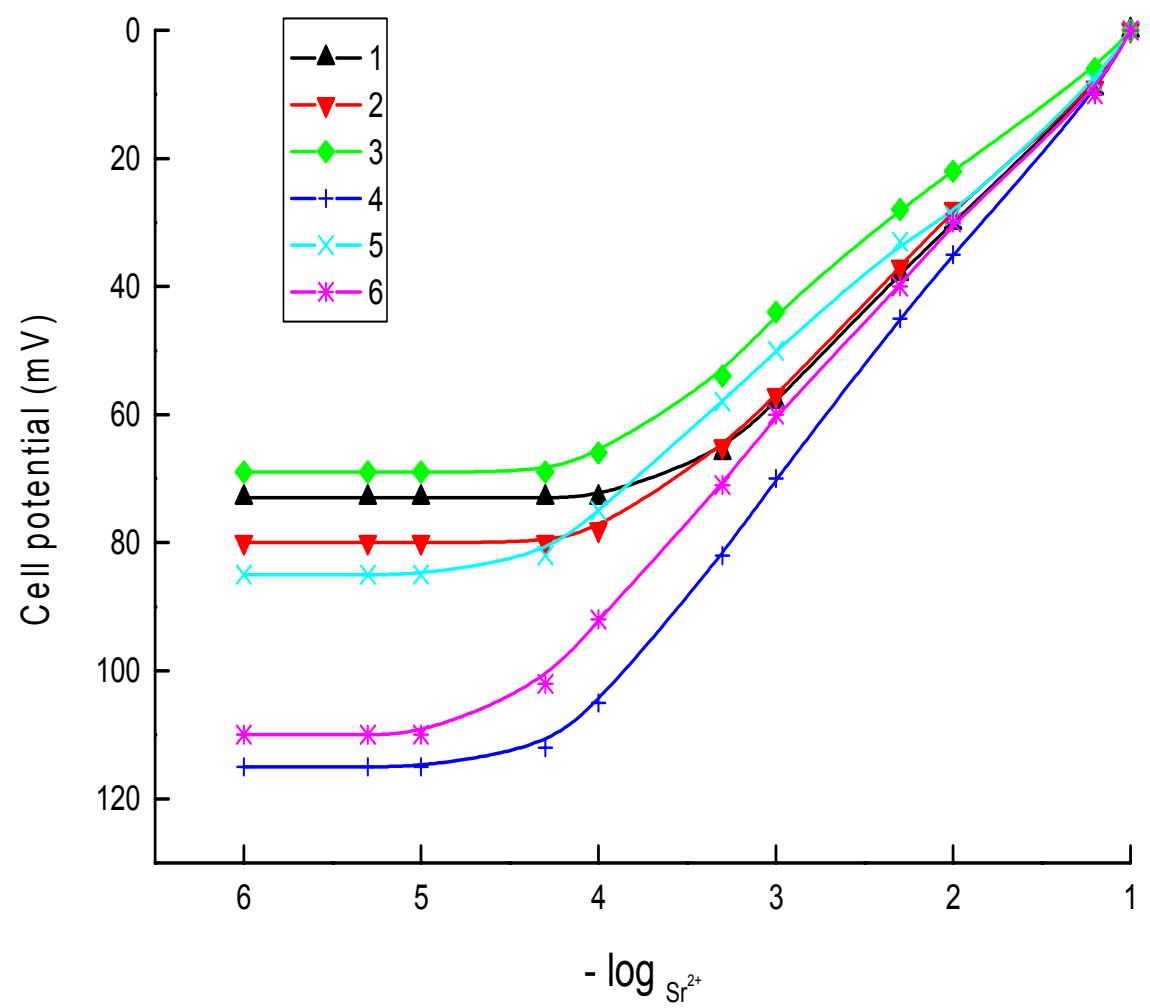

Figure 1. Variation of membrane potential with activity of $\mathrm{Sr}^{2+}$ ions, without solvent mediator (1), with solvent mediators DOP (2), TEP (3), DBBP (4), CN (5) and TBP (6).

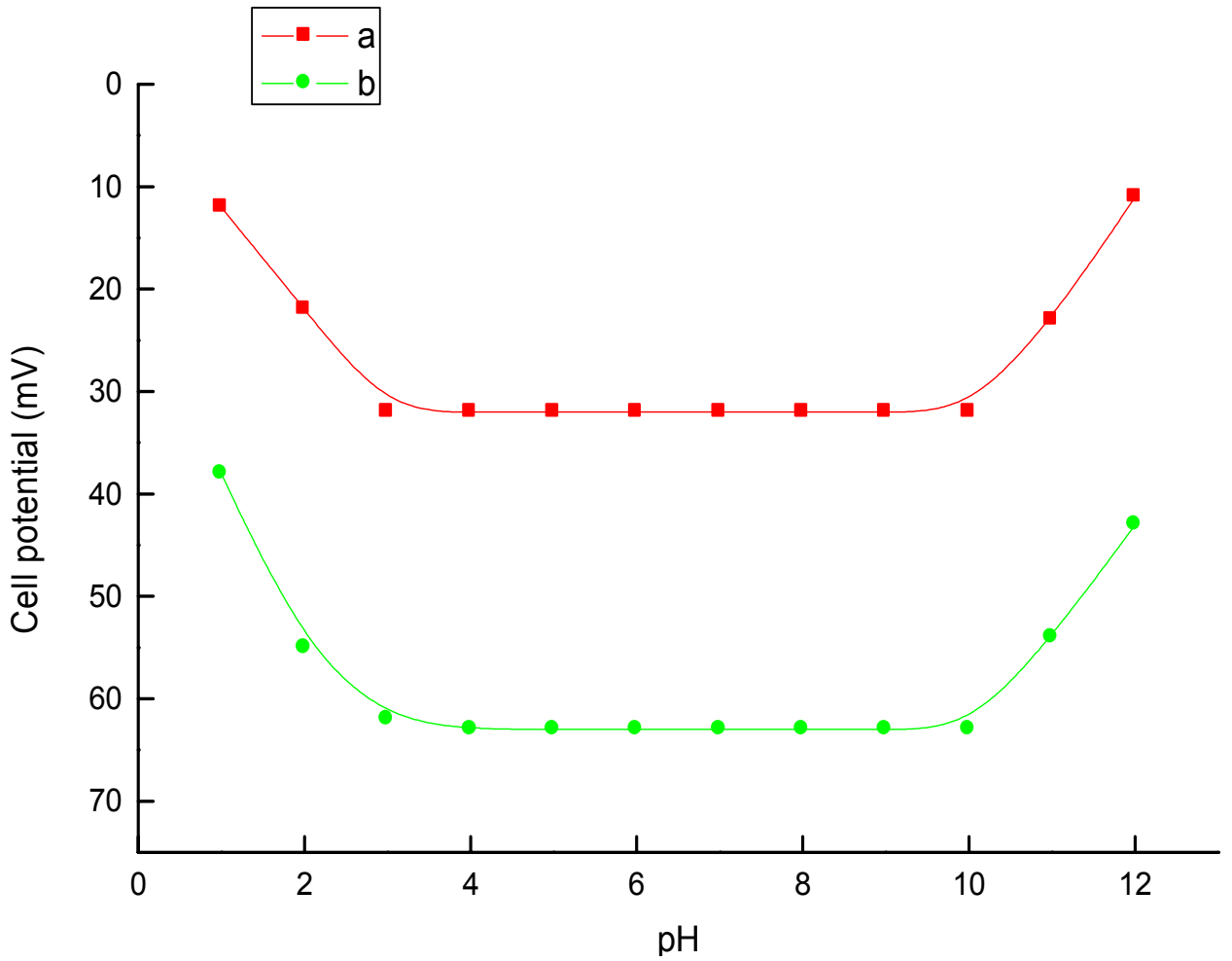

Figure 2. Effect of $\mathrm{pH}$ on cell potential; $\left[\mathrm{Sr}^{2+}\right]=1.0 \times 10^{-2}$ (a) and $1.0 \times 10^{-3} \mathrm{M}(\mathrm{b})$. 
The versatility of the sensor was further explored by studying its performance in partially non-aqueous media (methanol-water and ethanol-water mixtures) and the results are compiled in Table 2. The sensor does not show any appreciable change in the working concentration range and slope in mixtures having up to $25 \%(\mathrm{v} / \mathrm{v})$ non-aqueous content. Above $25 \%$ non-aqueous content, the working concentration range and slope of the sensor are considerably shortened. Further, the reproducibility of the potential data is reduced. Therefore, the sensor can be employed in mixtures having up to $25 \%(\mathrm{v} / \mathrm{v})$ non-aqueous content.

Table 2. Performance of $\mathrm{Sr}^{2+}$-selective sensor (No. 6) in partially non-aqueous medium.

\begin{tabular}{|c|c|c|}
\hline Non aqueous contents \% (v/v) & Slope $(\mathbf{m V} / \mathbf{d e c}.) \mathbf{( \pm \mathbf { 1 . 0 } )}$ & Working concentration range $(\mathbf{M})$ \\
\hline Nil & 30.0 & $3.2 \times 10^{-5}-1.0 \times 10^{-1}$ \\
\hline Methanol & & \\
\hline 5 & 30.0 & $3.2 \times 10^{-5}-1.0 \times 10^{-1}$ \\
\hline 10 & 30.0 & $3.2 \times 10^{-5}-1.0 \times 10^{-1}$ \\
\hline 15 & 29.6 & $3.9 \times 10^{-5}-1.0 \times 10^{-1}$ \\
\hline 20 & 29.6 & $3.9 \times 10^{-5}-1.0 \times 10^{-1}$ \\
\hline 25 & 29.0 & $5.0 \times 10^{-5}-1.0 \times 10^{-1}$ \\
\hline 30 & 25.0 & $1.9 \times 10^{-4}-1.0 \times 10^{-1}$ \\
\hline Ethanol & 30.0 & $3.2 \times 10^{-5}-1.0 \times 10^{-1}$ \\
\hline 5 & 30.0 & $3.2 \times 10^{-5}-1.0 \times 10^{-1}$ \\
\hline 10 & 30.0 & $3.2 \times 10^{-5}-1.0 \times 10^{-1}$ \\
\hline 15 & 29.8 & $3.6 \times 10^{-5}-1.0 \times 10^{-1}$ \\
\hline 20 & 29.0 & $5.0 \times 10^{-5}-1.0 \times 10^{-1}$ \\
\hline 25 & 26.4 & $1.0 \times 10^{-4}-1.0 \times 10^{-1}$ \\
\hline 30 & & \\
\hline
\end{tabular}

\section{Selectivity of the sensor}

The most important characteristic of any ion-selective sensor is its response to the primary ion in the presence of other ions of the solution; it is expressed as the selectivity coefficient $\left(\mathrm{K}^{\mathrm{Pot}} \mathrm{Sr}^{2+}{ }_{\mathrm{B}}\right)$. The selectivity coefficient was determined by the fixed interference method and is reported in Table 3 . A value of the selectivity coefficient equal to 1.0 indicates the same response to both the primary and interfering ion, whereas a value smaller than 1.0 reflects selectivity for the primary ion. It is seen from Table 3 that selectivity coefficient values are much smaller than 1.0. Thus, the electrode under consideration is sufficiently selective towards $\mathrm{Sr}^{2+}$ over alkali, alkaline earth metals and several common transition metal ions. The most important factor governing the selectivity characteristics of any ligand is the extent of preorganization and arrangement of the polar binding groups or atoms into a rigid conformation of optimum dimensions for the target ions [21]. The present ionophore in the membrane has highly polar ester groups, which hold the metal ion strongly into its cavity. From potentiometric selectivity data presented here, it is obvious that the present ionophore interacts strongly with $\mathrm{Sr}^{2+}$ ion and can be used 
successfully as sensing agent for a strontium sensor. Further, this sensor represents an improvement on already reported sensors based on 4-tert-butylcalix(8)arene, which showed a significant interference to $\mathrm{Na}^{+}$and $\mathrm{Pb}^{2+}$ ions, whereas the sensor under consideration shows an appreciable selectivity to $\mathrm{Sr}^{2+}$ over $\mathrm{Na}^{+}$and $\mathrm{Pb}^{2+}$ ions. In view of a good selectivity of the sensor, it can be used for $\mathrm{Sr}^{2+}$ determination in the presence of many foreign ions by direct potentiometry.

Table 3. Selectivity coefficient values observed for the $\mathrm{Sr}^{2+}$-selective sensor (No. 6) for various interfering ions (B) using fixed interference method.

\begin{tabular}{|c|c|}
\hline Interfering ion (B) & Selectivity coefficient $\left(\mathrm{K}^{\mathrm{pot}}{ }_{\mathrm{Sr}}{ }^{2+}, \mathrm{B}\right)$ \\
\hline $\mathrm{Na}^{+}$ & $2.0 \times 10^{-2}$ \\
\hline $\mathbf{K}^{+}$ & $2.5 \times 10^{-2}$ \\
\hline $\mathbf{R b}^{+}$ & $2.0 \times 10^{-2}$ \\
\hline $\mathrm{Cs}^{+}$ & $5.1 \times 10^{-2}$ \\
\hline $\mathbf{N H}_{4}^{+}$ & $3.2 \times 10^{-2}$ \\
\hline $\mathbf{A g}^{+}$ & $3.4 \times 10^{-2}$ \\
\hline $\mathrm{Ca}^{2+}$ & $3.2 \times 10^{-2}$ \\
\hline $\mathbf{M g}^{2+}$ & $5.0 \times 10^{-2}$ \\
\hline $\mathrm{Ba}^{2+}$ & $3.9 \times 10^{-2}$ \\
\hline $\mathrm{Ni}^{2+}$ & $2.0 \times 10^{-2}$ \\
\hline $\mathrm{Hg}^{2+}$ & $2.0 \times 10^{-2}$ \\
\hline $\mathbf{P b}^{2+}$ & $6.3 \times 10^{-2}$ \\
\hline $\mathbf{C d}^{2+}$ & $6.3 \times 10^{-2}$ \\
\hline $\mathrm{Cu}^{2+}$ & $3.2 \times 10^{-2}$ \\
\hline $\mathbf{M n}^{2+}$ & $3.2 \times 10^{-2}$ \\
\hline $\mathrm{Co}^{2+}$ & $3.9 \times 10^{-2}$ \\
\hline $\mathbf{Z n}^{2+}$ & $5.9 \times 10^{-2}$ \\
\hline $\mathrm{Cr}^{3+}$ & $3.0 \times 10^{-2}$ \\
\hline $\mathrm{Fe}^{3+}$ & $2.5 \times 10^{-2}$ \\
\hline $\mathbf{A l}^{3+}$ & $3.2 \times 10^{-2}$ \\
\hline
\end{tabular}

\section{Analytical application (titration)}

The sensor has been used as an indicator electrode for determining $\mathrm{Sr}^{2+}$ by potentiometric titration. For this purpose, a $10 \mathrm{ml}$ solution of $\mathrm{Sr}^{2+}\left(1.0 \times 10^{-3} \mathrm{M}\right)$ was titrated against EDTA solution $\left(1.0 \times 10^{-2} \mathrm{M}\right)$ at pH 10 using ammonia buffer, and the potentials obtained are plotted in Fig. 3. The titration plot is not conventional sigmoid-type because the sensor, though selective torwards $\mathrm{Sr}^{2+}$, is not specific to it and responds to a small extent to other ions. Thus, the sensor is responding mainly to the $\mathrm{Sr}^{2+}$ concentration and to some extent increase in the $\mathrm{Na}^{+}$-ion concentration (available from EDTA). The combined potential response leads to the plot achieved with a sharp break, which corresponds to a 1:1 stoichiometry of the Sr- 
EDTA complex. This type of behavior is characteristic for many ISEs, which are not specific to the primary ion and have been used to determine the concentration of primary ions by potentiometric titration [22-24]. Thus, the present sensor might be used as an indicator electrode for determining $\mathrm{Sr}^{2+}$ by potentiometric titration.

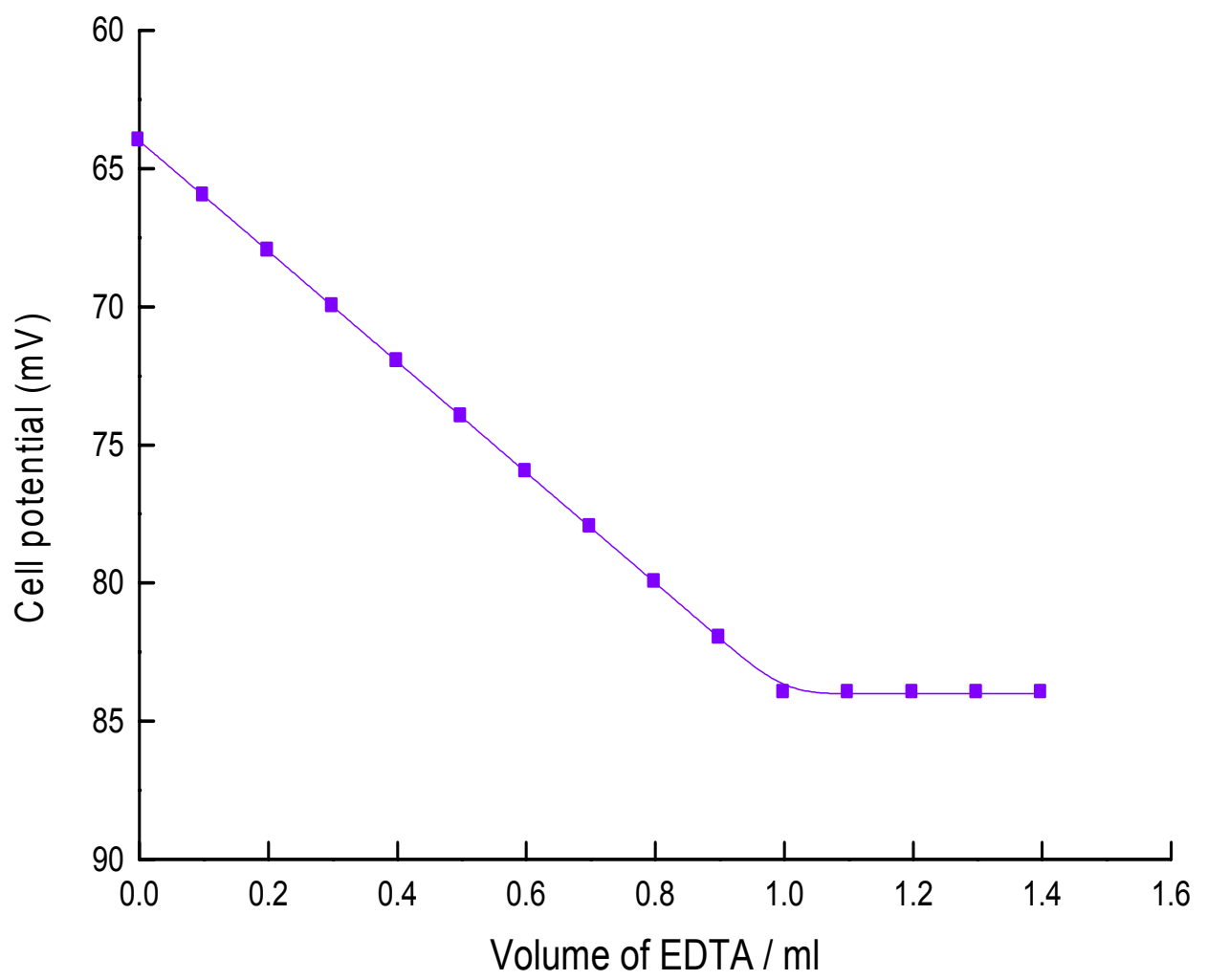

Figure 3. Potentiometric titration plot of $1.0 \times 10^{-3} \mathrm{M} \mathrm{Sr}^{2+}$ solution $(10 \mathrm{ml})$ with EDTA $\left(1.0 \times 10^{-2} \mathrm{M}\right)$.

\section{Conclusions}

The investigation carried out on a number of membranes for a $\mathrm{Sr}^{2+}$-selective sensor shows that one with the composition 5:2:150:100 (I: NaTPB: TBP: PVC (w/w)) gives the best performance in terms of reproducibility and other sensor characteristics. The sensor based on this membrane shows a wide working concentration range $\left(3.2 \times 10^{-5}-1.0 \times 10^{-1} \mathrm{M}\right)$, a fast response time $(10 \mathrm{~s})$, a good selectivity to $\mathrm{Sr}^{2+}$, a wide $\mathrm{pH}$ range (3-10), an adequate shelf life ( 4 months) and it works well in partially nonaqueous medium containing up to $25 \%(\mathrm{v} / \mathrm{v})$ non-aqueous content (methanol and ethanol). Most reported electrodes [6-13,15] generally showed an interference to $\mathrm{Ba}^{2+}, \mathrm{Hg}^{2+}, \mathrm{K}^{+}, \mathrm{Na}^{+}$, and $\mathrm{Pb}^{2+}$ ions and exhibit a large response time, a small $\mathrm{pH}$ range and a short life time. The sensor under consideration is an improvement over existing sensors in that: (i) it does not show a significant interference to $\mathrm{Ba}^{2+}, \mathrm{Hg}^{2+}, \mathrm{K}^{+}$, $\mathrm{Na}^{+}$, and $\mathrm{Pb}^{2+}$ ions, (ii) it functions satisfactorily over a wide $\mathrm{pH}$ range (3-10), (iii) it has a longer shelf life $\left(\sim 4\right.$ months) and (iv) it shows a faster response time (10 s). Thus, the sensor prepared can be used for $\mathrm{Sr}^{2+}$ determination by direct potentiometry or potentiometric titration. 


\section{Acknowledgement}

One of the authors (J.R.R.) is grateful to the Ministry of Human Resource Development (MHRD), New Delhi, for providing financial assistance.

\section{References}

1. Bureau of Mines, Mineral Commodity Summaries 1986, 152.

2. Browning, E. 2nd Ed. New York: Appleton Century Crofts, Toxicity of Industrial Metals 1969, 302.

3. Shamsipur, M.; Mojtaba, R.; Raoufi, F. Preconcentration and separation of trace amounts of strontium ions from alkali and alkaline earth metal ions using octadecyl-18-crown-6 and its determination by flame atomic absorbtion spectrometry. Mikrochimica Acta, 2001, 137, 163.

4. Bondareva, N.V.; Zolotoritskaya, E.S. Flame-emission-photometric determination of rare alkali and alkaline earth metals in drinking water and waste waters. Zavodskaya Laboratoriya, 1991, 57, 36.

5. Tarun, D.K.; Sarin, M. Trace determination of strontium and barium in river waters by inductively coupled plasma-atomic emission spectrometry using an ultrasonic nebulizer. Geostandards Newsletter, 2002, 26, 301 .

6. Baumann, E.W. Preparation and properties of strontium selective electrode. Anal. Chem., 1975, 47, 959.

7. Akmal, N.; Zimmer, H.; Mark, H.B. Strontium ion selective electrode based on a conducting poly(dibenzo-18-crown-6) Film. Anal. Lett., 1991, 24, 1431.

8. Singh, A.K.; Bhattacharjee, G.; Baniwal, S.; Singh, M. A New PVC based membrane sensor of dibenzo-18-crown-6 for strontium. J. of Indian Chem. Society, 1999, 76, 53.

9. Shamsipur, M.; Rouhani, S.; Sharghi, H.; Ganjali, M.; Eshghi, H. Strontium selective membrane electrodes based on some recently synthesized benzo substituted macrocyclic diamides. Anal. Chem., 1999, 71, 4938.

10. Jain, A.K.; Srivastava, S.K.; Singh, R.P.; Agarwal, S. Studies with inorganic ion exchange membranes - a membrane selective to strontium ion. J. Appl. Chem. Biotechnol., 1977, 27, 680.

11. Srivastava, S. K.; Jain, C. K. A solid membrane electrode for strontium ions. Bunseki Kugaku, 1984, 525.

12. Beg, M.A.; Usman, M.; Nabi, A. Ion selective characteristics of heavy metal myristate liquid membrane electrode. Electroanalytical Chemistry and Interfacial Electrochemistry, 1980, 112, 347.

13. Faizan, N.; Chattopadhyaya, M.C. Heterogeneous precipitates based strontium (II) membrane ion selective electrode. J. Institution Chemists (India), 1990, $62,95$. 
14. Gutsche, C.D. Calixarene, RSC Monographs in Supramolecular Chemistry, No.1, Royal Society of Chemistry, Cambridge 1989; Gutsche, C.D. In; Calixarenes Revisited in Monographs in Supramolecular Chemistry (Ed: F. Stoddart) The Royal Society of Chemistry, Cambridge, UK, 1998.

15. Gupta, V.K.; Jain, A.K.; Khurana, U.; Singh, L.P. PVC based neutral carrier and organic exchanger membranes as sensors for the determination of $\mathrm{Ba}(\mathrm{II})$ and $\mathrm{Sr}(\mathrm{II})$. Sens. Actuators B, 1999, 55, 201.

16. Lynch, A.; Eckhard, K.; McMahon, G.; Wall, R.; Kane, P.; Nolan, K.; Schuhmann, W.; Diamond, D. Cation binding selectivity of partially substituted calix[4]arene esters. Electroanalysis, 2002, 14, 1397.

17. Kane, P.; Kincaid, K.; Fayne, D.; Diamond, D.; McKervey, M.A. Modeling metal complexes of calixarene esters and phosphine oxides using molecular mechanics. Journal of Molecular Modeling, 2000, 6, 272.

18. Namor, A.F.; Gil, E.; Tanco, M.A.; Tanaka, D.A.; Salazar, L.E.; Schulz, R.A.; Wang, J. Thermodynamics of calix[4]arene esters. 1. complexation of alkyl p-tert-butylcalix[4]arenetetraethanoates and alkali metal cations in acetonitrile and in benzonitrile. Journal of Physical Chemistry, 1995, 99, 16776.

19. Cadogan, A.; Diamond, D.; Smyth, M.R.; Svehla, G.; McKervey, M.A.; Seward, E.M.; Harris, S.J. Caesium-selective poly(vinyl chloride) membrane electrodes based on calix[6]arene esters. Analyst, 1990, 115, 1207.

20. Moody, G.J.; Thomas, J.D.R. Selective ion sensitive electrodes, Merrow Publishing, 1971.

21. Cadogan, A.; Diamond, D.; Smyth, M.R.; Deasy, M.; McKervey, M.A.; Harris, S.J. Sodium selective polymeric membrane electrodes based on calix[4]arene iopnophores. Analyst, 1989, 114, 1551.

22. Jain, A.K.; Gupta, V.K.; Sahoo, B.B.; Singh, L.P. Copper(II) selective electrodes based on macrocyclic compounds. Anal. Proceeding Including Anal. Comm., 1995, 32, 99.

23. Jain, A.K.; Gupta, V.K.; Singh, L.P.; Khurana, U. Macrocycle based membrane sensors for the determination of cobalt(II) ions. Analyst, 1997, 122, 583.

24. Jain, A.K.; Sondhi, S. M.; Rajvanshi, S. A PVC based hematoporphyrin IX membrane potentiometric sensor for zinc. Electroanalysis, 2002, 14, 293.

(C) 2004 by MDPI (http://www.mdpi.org). Reproduction is permitted for non-commercial purposes. 